\title{
XIII. Improved construction of the movable-coil galvanometer for determining current-strength and electromotive force in absolute measure
}

\section{Dr. Eugen Obach}

To cite this article: Dr. Eugen Obach (1883) XIII. Improved construction of the movable-coil galvanometer for determining current-strength and electromotive force in absolute measure , Philosophical Magazine Series 5, 16:98, 77-90, DOI: 10.1080/14786448308627401

To link to this article: http://dx.doi.org/10.1080/14786448308627401

曲 Published online: 28 Apr 2009.

Submit your article to this journal $[\pi$

ЏII Article views: 2

Q View related articles $\sqsubset$ 


\title{
LONDON, EDINBURGH, AND DUBLIN
}

\section{PHILOSOPHICAL MAGAZINE}

\author{
AND \\ JOURNAL OF SCIENCE.
}

[FIFTH SERIES.]

$$
\text { AUGUST } 1883 .
$$

XIII. Inproved Construction of the Movable-coil Galvanometer for determining Current-strength and Electromotive Force in Absolute Measure. By Dr. Eugen Obact*.

SOME years ago I showed that the tangent-galvanometer of $N$ ordinary dimensions may be employed as a measuring instrument for very strong currents if the ring is made movable around its horizontal diameter $\dagger$, a principle already adopted before that time by Prof. Trowbridge, of Harvard College, Massachusetts $\ddagger$; a little later I described a galvanometer based upon that principle, and constructed by Messrs. Siemens Brothers $\S$.

I now propose to give a brief account of several alterations which have since been introduced by that firm, and which I venture to think render the instrument more sensitive and more convenient for use, besides creating for it a wider field. As the galvanometer, in the complete form in which I shall presently describe it, is not so much destined to meet the daily want of the practical electrician, but is rather intended for measurements where greater accuracy and trustworthiness than usual is necessary, I thought myself justified in bringing the subject before the Physical Society, particularly as the kindness

* Communicated by the Physical Society ; read June 9, 1883.

† 'Nature,' xviii. p. 707 (1878); Repertor. für Exper. Physik. xiv. p. 507 (1878).

f Amer. Journ. of Arts and Science, vol. ii. (August 1871).

$\$$ Zeitschrift für angewandte Electricitätslehre, i. p. 4 (1879).

Phil. Mag. S. 5. Vol. 16. No. 98. August 1883. 
of Messrs. Siemens Bros. \& Co. at the same time enables me to place the instruments before you for inspection.

Ere proceeding further, allow me to say that I shall not on this occasion touch upon the theory of the instrument, which is already given elsewhere, but confine myself wholly to describing the recent improvements in its construction, adding a few series of measurements in order to prove the high degree of accuracy obtainable.

I propose to deal with the different parts of the instrument under separate headings; and will first speak of

\section{The Magnetic Needle and its Potnter.}

The older instruments had a flat magnetic needle fixed to a light vertical axle, pivotted at both ends between jewels to prevent any dipping, which the needle would otherwise experience with great inclinations of the ring. This arrangement answered sufficiently well with ordinary care; but still the delicate pivots were likely to be damaged, thus impairing the sensitiveness of the needle. As now constructed, the dipping of the needle is completely avoided in the manner illustrated by the annexed figure. The needle, $n s$, is fixed to a thin

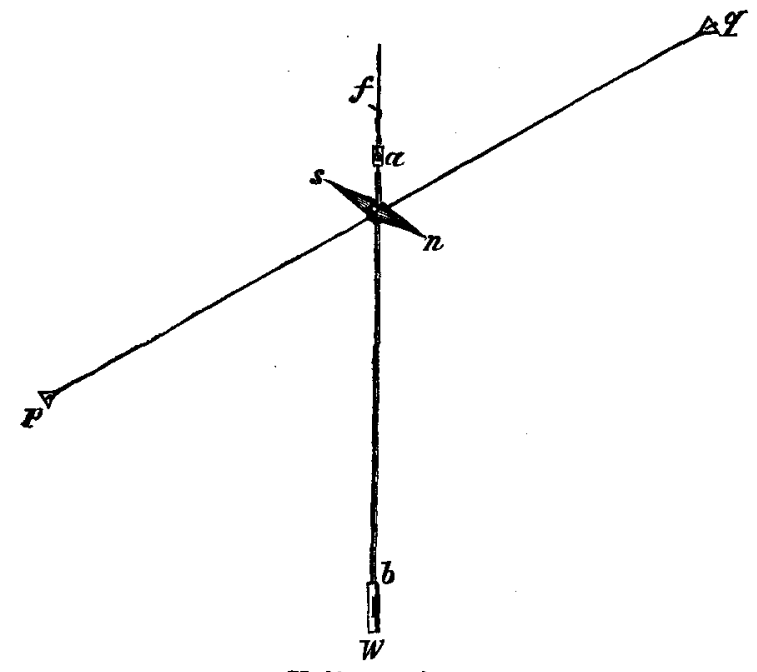

Half nat. size.

vertical axle, $a b$, near its upper end, the lower end of the axle being provided with a cylindrical brass weight, $w$. This weight offers but little additional momentum to the whole system round the vertical axis, whereas the movement round the horizontal axis is completely prevented. The aluminium 
pointer, $p q$, is situated in the same plane as the scale; the ends are flattened and provided with a fine slit, which serves as an index for reading the deflections, the bottom of the needle-box being blackened. The reading can thus be taken without parallax, and therefore very accurately. The magnetic needle has a biconical shape, which entirely prevents the shifting of the magnetic axis from its original position, as was sometimes found to be the case with the old broad needles. Adjustments are provided by which the cocoonfibre, $f$, serving to suspend the needle, can be raised or lowered, as well as accurately centred.

\section{The Damping of the Oscillations.}

Numerous experiments were undertaken to ascertain a convenient method for damping the oscillations of the needle, and to arrive, if possible, at a perfectly aperiodical movement. After trying large masses of copper placed in the immediate neighbourhood of the swinging magnet, as well as liquid damping, without decided success, air-damping was resorted to, and finally adopted. It will be remembered that Sir William Thomson used air-damping for the light-mirror of his dead-beat galvanometer, and Prof. Töpler * for other galvanometric apparatus. In our case the air-chamber consists of a shallow cylindrical box, about 8 centim. in diameter, $1 \frac{1}{4}$ centim. high, provided with two radial partitions which can be slid in or out; the axle of the needle, passing through the centre of this box, carries a light and closely fitting vane. By sliding the partitions more or less into the box various degrees of damping can be obtained; and if they are right in, the motion is practically dead-beat.

\section{The Scales.}

Declination-scale.-This scale, engraved on a horizontal ring, was formerly divided into degrees, as usually done; but now one semicircle is provided with divisions corresponding to the natural tangents. The interval between each two divisions must of course vary for different parts of the scale, and is arranged as follows:-

\section{TABLE I.}

Values of tangent.

0 to 1

1,2

2,3

3,5
Interval.

0.01

$0 \cdot 02$

$0 \cdot 05$

$0 \cdot 10$

* Repert.f. exp. Phys. ix. p. 259 (1873). $\mathrm{H} 2$ 
It will be noticed that the value of the interval only changes at those places where the tangent is equal to a whole figure, thus making a mistake in reading less likely. Looking at this scale no gaps are conspicuous, and the divisions are everywhere pretty evenly distributed. Tangent-scales have been employed by Joule, Sir William Thomson, and others; but the one now described seems well to satisfy all the requirements.

Inclination-scale.-This scale, engraved on a vertical quadrant divided into degrees, can accurately be read to one tenth by means of a vernier. The zero division was formerly that to which the index pointed when the ring was horizontal. In this case the tangent of the deflections had to be divided by the sine of the angles. For convenience' sake, the places were specially marked on the scale at which the sines corresponded to whole figures. The new inclination-scale has the zero at the vertical or normal position of the ring; and instead of the sines, the secants are specially marked which are represented by whole figures. With these secants the tangents of the deflections must be multiplied; and they can therefore be termed multiplying powers, analogous to the multiplying power of shunts. The instruments intended only for the measurement of current-strength have the quadrant bearing the secant-scale fixed outside the ring, whilst the others, measuring also electromotive force, have it situated between the needle-box and the ring, where it is better protected from injury.

If the deflections of the needle are read on the tangentscale and the positions of the ring on the secant-scale, the aid of trigonometrical tables may be entirely dispensed with, as the product of the two figures represents the quantity to be measured, irrespective of a constant.

\section{The Solid Ring and the Coll.}

If the galvanometer has to serve only for the measurement of currents, the gun-metal ring is of a rectangular cross section; but if it is at the same time destined to measure difference of potential, the cross section is $\mathbf{V}$-shaped, the groove being filled with numerous turns of G.S. wire. If the number of convolutions is known, and if a simple relation exists between that number and the resistance of the wire, a great advantage may be derived therefrom. For instance, if there are one thousand convolutions on the coil, offering a resistance of exactly one thousand ohms, the current due to the difference of potential of one volt at the ends of the coil would produce the same deflection of the needle as the current of one ampère flowing through the solid metal ring. That this must be so 
is evident, if it is remembered that the weak current of one thousandth of an ampère flows round the needle one thousand times, but the stronger current of one ampère only once. The solid ring and the convolutions are thus arranged that their cross sections have a common centre of gravity, thus both acting exactly in the same way upon the magnetic needle. If this simple plan is adopted, the calibration of the galvanometer for difference of potential in volts, which is readily performed with a few cells of known E.M.F., at the same time gives the graduation of the instrument for strength of current in amperes. I have been using various modifications of the Daniell cell with solutions of copper and zinc sulphate of equal specific gravity. At present I am engaged in constructing a standard cell for such purposes, which is always at disposal; and, as far as the preliminary experiments show, the E.M.F. of the new cell will closely approach one volt. Further on I shall communicate some measurements, by which I intend to show how accurately the calibration of the fine-wire coil in volts can serve for that of the solid ring in amperes.

\section{The Constant Shunt and Leading Wires.}

With the size of the ring usually employed, viz. 30 centim. diameter, and our horizontal component of the earth's magnetism, currents of greater strength than about 50 amperes would require the ring to be at the multiplying powers 9 or $10, i$. $e$. near the horizontal position. If, as a rule, such currents have to be measured, it is desirable to raise the constant of the galvanometer, say two or threefold, without a proportionate increase of the dimensions. This can be done by the use of a so-called "constant shunt," thereby allowing only half or one third of the current to flow round the needle. In our case the shunt is made of exactly the same metal as the solid ring itself; it has no soldering-places, and consists in fact of three or four little bridge pieces left standing instead of cutting the ring quite open where the terminals join. By comparison with an instrument of the same description having an open ring, the shunt can be adjusted to any power desirable.

However, by the introduction of the "constant shunt" the accuracy of the measurements is somewhat impaired. Experiments in which the shunt-pieces were touched with a thin stick of low-melting material during the passage of very strong currents, proved that they did not become hot, on account of their extremely low absolute resistance and their contact with the large metallic mass of the ring conducting away the heat. Variations of temperature, to which both the ring and the 
shunt are subjected, do not of course in the least disturb the ratio of their resistance, since they both consist of the very same alloy.

As the current only passes round the needle once and, if powerful enough, produces deflections even if the ring is almost horizontal, it is hardly necessary to call attention to the fact that the wires leading the current to the instrument should be so arranged that they cannot act upon the needle; still I have seen instances where this simple and almost selfevident precaution has been strangely neglected. I thought it therefore best to have special leading wires provided which are absolutely inactive upon the needie, and may therefore be named "adynamic leads." These leads consist of a number of well-insulated copper wires stranded together in a peculiar manner, and covered with a cotton braiding, similar to the ordinary speaking-tubes. The cable thus formed is quite flexible, and without the slightest action upon a magnetic needle. I sent a strong current through several turns of such a cable, and held it close to a delicately suspended magnetic needle, but could not detect any effect whatever upon it. One half of the wires is covered with a differently coloured material to the other half ; and the wires of each colour are united at both ends of the cable, and there soldered to a stout piece of copper wire. The adynamic cable can be made in any length and for different current-strengths; and as it offers only a small resistance, it can be employed to convey the current to be measured to a locality where the needles are not disturbed by machines or wires.

\section{The Adjusting Parts and the Compensating Magnet.}

With regard to the adjustment of the instrument, it suffices to say that, besides the necessary levelling-arrangements, it is provided with clamp-rings for tightly holding the pillar as well as the morable coil without interfering with previous adjustments, and in the same manner as is often done with mathematical apparatus. The final adjustment of the axis of the coil into the meridian is performed by means of a fine screw, which proves very useful for correcting, during a series of measurements, the occasional variations of the zero position.

As long as the galvanometer stands in the same position, the "constant," as a rule, changes but little even from day to day. If, however, the instrument is taken from one place to another, great changes in that respect will occur, amounting sometimes to many per cents. These changes do not of course interfere with the accuracy of the measurements, because the "constant" can easily be redetermined with a known E.M.F. 
at any place, as we have seen; but it would undoubtedly be very convenient to have the galvanometer of equal sensibility everywhere. For that purpose an auxiliary magnet is placed east or west from the needle in a plane parallel to the meridian, which can turn round a horizontal axis passing through its neutral point and the centre of the needle, and being at right angles to the diameter on which the coil is turned. 'l'his magnet does not affect the zero position, and moreover, if placed exactly vertical with its magnetic axis, it does not alter the original constant, which then only depends upon the horizontal terrestrial component, more or less modified by the surroundings; but if it is dipped, the horizontal force acting on the needle is either augmented or diminished, according to the direction in which the magnet is turned and to the amount of dip given. It is easily seen that the magnetic influence of the surroundings upon the needle may now greatly vary from one place to another and still be compensated by the magnet, thus keeping the so-called "constant" of the galvanometer actually at a constant value, adjusting it, for instance, always so that the unit deflection of $45^{\circ}$ with the vertical ring corresponds to a round number of volts and ampères, say five or ten. Under such conditions the deflection-scale could at once give the current or E.M.F. in ampères or volts. A gradual change of magnetism in the compensating magnet does not affect the measurements. I shall not further enter into this subject here, as I intend discussing it more fully on a future occasion.

\section{Methods of Measurement.}

For measuring current-strength or electromotive force either of the following four methods can be employed according to circumstances, viz.:-

I. The General Method.-Applicable under almost any conditions. The coil is placed in such a position that the deflection attains a proper value. If $\alpha$ is the deflection of the needle, and $\phi$ that of the coil from the meridian, the formula is

$$
x=\tan \alpha \times \sec \phi \times \text { const.; }
$$

or in case the multiplying powers $\mathrm{P}$ on the quadrant are used, the formula becomes

$$
x=\tan a \times P \times \text { const. }
$$

II. Method of Equality.-With this method the coil is each time placed in such a position that the needle is deflected exactly to the same angle $\psi$ to which the coil is inclined, giving the formula

$$
x=\tan \psi \times \sec \psi \times \text { const. }
$$


Having then only to deal with a single angle for a particular measurement, these products of tangents and secants may be calculated beforehand. For this purpose the natural sines are sufficient, because $\tan \times \sec =\frac{\sin }{\cos ^{2}}$.

The following Table gives, for easy comparison, the values of tangents, secants, and their products at ten and multiples of ten degrees. These products, like the tangents, range from nil to infinity, but increase more rapidly.

TABLE II.

\begin{tabular}{|c|c|c|c|c|c|c|c|c|c|c|}
\hline Angle. & $0^{\circ}$ & $10^{\circ}$ & $20^{\circ}$ & $30^{\circ}$ & $40^{\circ}$ & $50^{\circ}$ & $60^{\circ}$ & $70^{\circ}$ & $80^{\circ}$ & $90^{\circ}$ \\
\hline $\tan \ldots \ldots$ & 0 & $\cdot 176$ & $\cdot 364$ & $\cdot 577$ & 839 & $1 \cdot 192$ & 1.732 & $2 \cdot 747$ & $5 \cdot 671$ & $\infty$ \\
\hline $\sec \ldots .$. & $1 \cdot 0$ & 1.015 & 1.064 & $1 \cdot 155$ & $1 \cdot 305$ & 1.556 & $2 \cdot 000$ & 2924 & $5 \cdot 759$ & $\infty$ \\
\hline $\tan \times 8 \theta c$ & 0 & $\cdot 1786$ & .3873 & 6664 & 1.095 & $1 \cdot 855$ & $3 \cdot 464$ & 8.032 & $32 \cdot 66$ & $\infty$ \\
\hline
\end{tabular}

III. Method of Constant Deflection.-Here the coil is each time inclined until the needle reaches a certain deflection, say $26 \frac{1}{2}^{\circ}, 45^{\circ}$, or $63 \frac{1}{2}^{\circ}$, of which the corresponding tangents are $\frac{1}{2}$, 1 , and 2 respectively. This figure then enters the constant, giving the simpler formula

$$
x=\sec \phi \times \text { const., }
$$

the instrument acting as a secant-galvanometer. For a given constant deflection the secant-measurements range between unity and infinity, as the above little table shows. This method has the peculiarity that the needle occupies a fixed position in space during the measurements, which in some instances may be found of advantage.

IV. Method of Constant Inclination.-In this case the coil is fixed at a given inclination, and sec $\phi$ enters the constant; thus the formula is reduced to that of the ordinary tangentgalvanometer,

$$
x=\tan \alpha \times \text { const. }
$$

As compared with other galvanometers proposed for a similar purpose, the one here described offers the great advantage that the magnetic needle has not to be shifted from one measurement to another, whereby the magnetic field may sometimes considerably alter; furthermore it does not depend 
upon the constancy of permanent magnets, which, to say the least, is rather precarious*.

\section{Numerical Results of Measurements.}

I shall now communicate some measurements and tests to which the latest forms of instruments have been subjected, in order to illustrate the degree of accuracy obtainable. The first set was undertaken to ascertain the relation actually existing between the solid ring for currents and the coil of wire for E.M.F., which, it will be remembered, was intended to be such that amperres with the solid ring should accurately correspond to volts with the wire coil. The experiment was conducted as follows:-A current, from my constant battery with acid flow $\dagger$, was sent through the solid ring and a copper voltameter in circuit for a certain time, the deflections to the right and left being observed every five minutes. The mean of these deflections was taken as corresponding to the amount of copper deposited. The copper-sulphate solution and the electrodes consisted of pure materials. The mean of the gain of the kathode and the loss of the anode was taken. The amount corresponding to one ampère per hour is 1.164 gramme of copper or 3.96 grammes of silver, the latter figure being that adopted by Messrs. Siemens and Halske, of Berlin $¥$. The calibration of the fine-wire coil for volts was performed by means of a number of Daniells, each compared with a Raoult's standard cell filled with pure sulphate solutions and having the E.M.F. 1·115 volt, according to Dr. Alder Wright's experiments $\S$. The figures obtained were as follows:-

a. With the solid Ring.

Copper obtained $=11.435$ grammes.

Time of electrolysis $=60$ minutes.

Mean deflection $=47^{\circ} \cdot 3$.

Position of ring $P=2$.

Hence the current corresponding to the unit deflection of $45^{\circ}$ with the ring vertical $=4.531$ ampères.

b. With the fine-wire Coil.

Number of Daniells $=4$.

E.M.F. thereof $=4 \times 1 \cdot 109$.

Deflection obtained $=44^{\circ} \cdot 6$.

Position of coil $\mathrm{P}=1$.

* Another advantage undoubtedly is that the galvanometer requires no variable shunt, by which errors may very easily be introduced.

+ Rep.f. exp. Phys. xviii. p. 633 (1882).

See latest instructions for use of their torsion galvanometers.

§ Proc. Phys. Soc. v. p. 80 (1882). 
Hence the E.M.F. corresponding to the deflection of $45^{\circ}$ with the ring vertical $=4.525$ volts, the correction for the resistance of the cells being applied.

These two results agree very closely indeed, showing only a difference of 0.13 per cent. This is the more remarkable as the two kinds of measurements have nothing in common, being in fact based upon data quite independent of each other, thus proving that it is admissible to substitute for such instruments the calibration in volts for that in amperes.

A further series given in Tables III. and IV., and carried out with great care, clearly show that, for any given currentstrength or E.M.F., the result of the measurement is almost identical in whatever region the readings are taken.

Table III. is obtained with currents from my constant battery passed through the solid ring. The six different currentstrengths were obtained by the insertion of suitable resistances, and were as nearly as possible in the proportion of the whole figures 1 to 6 .

Table IV. contains measurements with the fine-wire coil, thereby using the E.M.F. of ordinary Bunsen cells connected in series, and varying in number from 2 to 12.

From these Tables it will be seen that, on the one hand, the deflections extend over the greater part of the tangent-scale, i. e. from $3^{\circ} \cdot 4$ till $78^{\circ} \cdot 2$, and, on the other, the position of the coil varies from the multiplying power 1 to 10 - the quantities measurable being therefore in the proportion of 1 to 500 , yet the accuracy arrived at may be pronounced fully satisfactory. Combining the results of all these measurements with the solid ring and with the wire coil, the mean error of a single reading becomes 0.35 per cent, and the probable error 0.24 per cent.

The last set of measurements had for its object to show that a compensating-magnet of the description proposed does not affect the readings. The results are embodied in Table V.; they were obtained with one of the older forms of solid-ring galvanometers provided with a sine-scale. The curved controlling magnet of a mirror-galvanometer, 20 centim. long and 2 centim. broad, was strongly magnetized and placed at a distance of 24 centim. in the manner formerly specified, and so arranged that it could be turned on a horizontal axis. Three different positions were given to the magnet-viz. one, in which it assisted the earth's magnetism, another, in which it did not act upon the needle, and a third, in which the earth's magnetism was partly neutralized. By altering the resistance in circuit, the deflections with the vertical ring were made equal in all three cases, viz. $63^{\circ} \cdot 5$. 


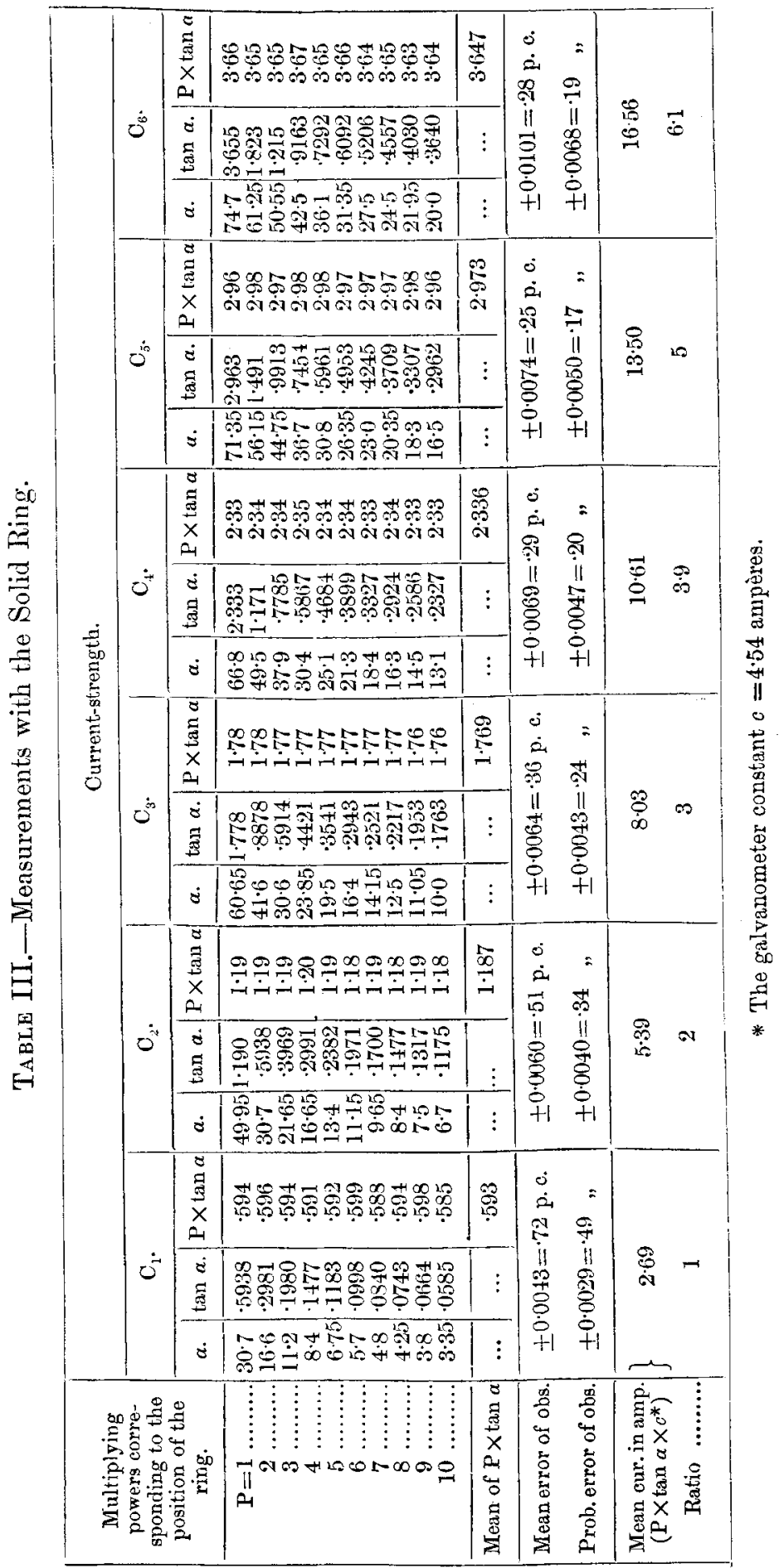




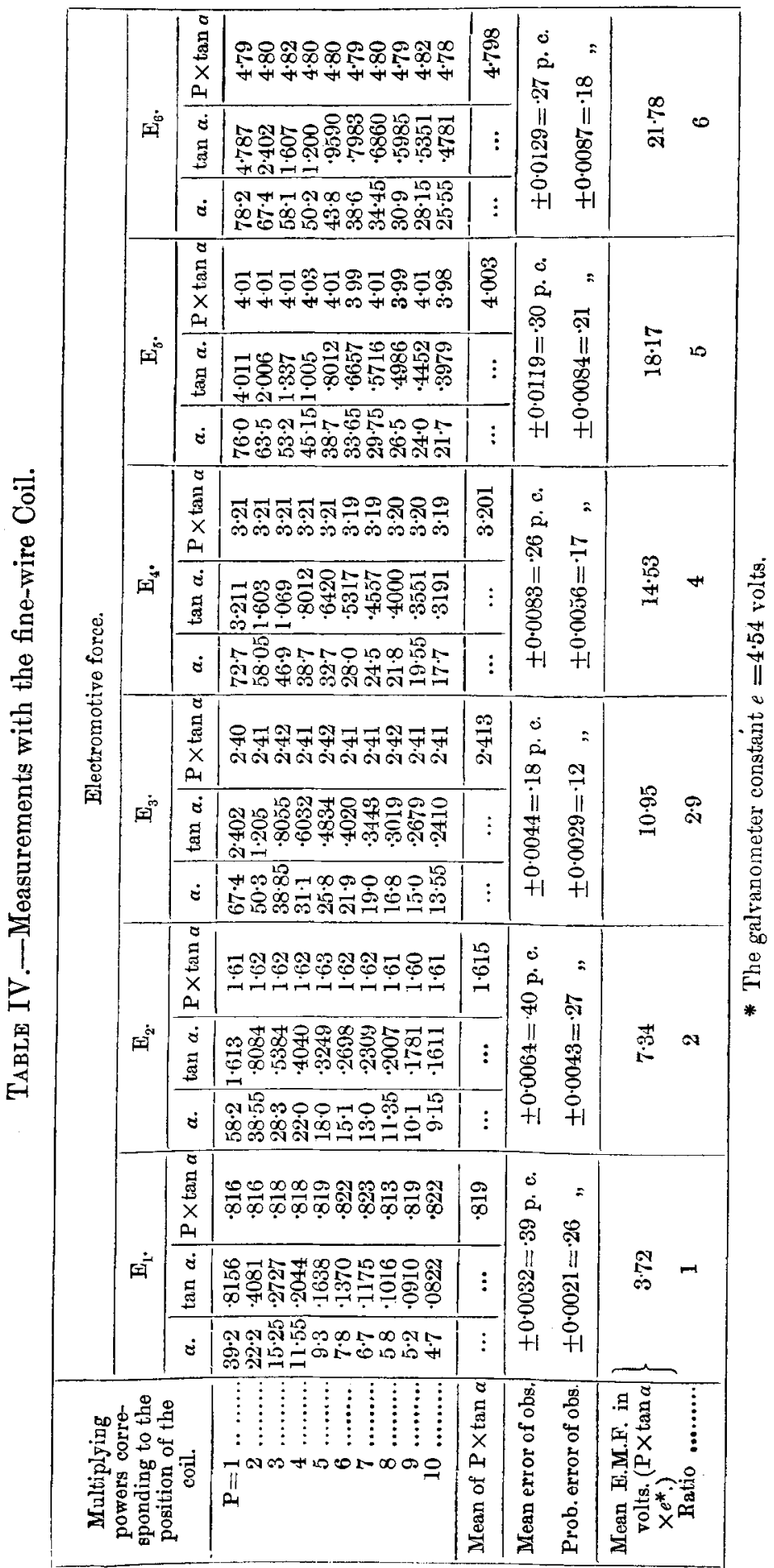


Construction of the Movable-coil Galvanometer.

\begin{tabular}{|c|c|c|c|c|c|c|c|}
\hline \multicolumn{2}{|c|}{ 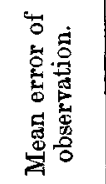 } & $\begin{array}{l}\stackrel{2}{8} \\
\stackrel{0}{0} \\
+1\end{array}$ & $\begin{array}{c}\dot{0} \\
\dot{0} \\
\stackrel{1}{a} \\
\dot{0}\end{array}$ & 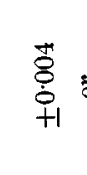 & \begin{tabular}{l}
$\dot{0}$ \\
$\dot{8}$ \\
\multirow{2}{0}{} \\
0
\end{tabular} & 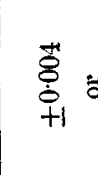 & $\begin{array}{l}\dot{0} \\
\dot{0} \\
\dot{8} \\
\dot{0}\end{array}$ \\
\hline \multicolumn{2}{|c|}{ 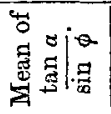 } & \multicolumn{2}{|c|}{ 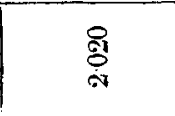 } & \multicolumn{2}{|c|}{$\underset{\mathscr{C}}{\grave{i}}$} & \multicolumn{2}{|c|}{$\stackrel{\oplus}{\circ}$} \\
\hline \multirow{6}{*}{ 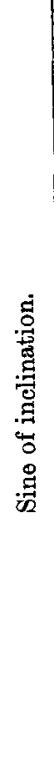 } & $\stackrel{9}{-1}$ & 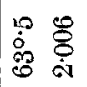 & ڤ્ڤ & 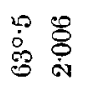 & ڤ્ڤ & 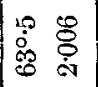 & فे \\
\hline & 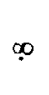 & 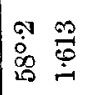 & ڤ્ڤ & $\begin{array}{ll}0 & 8 \\
0 & 8 \\
0 & 0 \\
0 & \stackrel{-1}{10}\end{array}$ & $\stackrel{8}{\leftrightarrow}$ & $\mid \begin{array}{ll}0 & 0 \\
\dot{0} & 0 \\
\infty & 0 \\
20 & \dot{-1}\end{array}$ & §ิํํ \\
\hline & بִ & 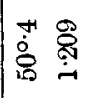 & $\stackrel{\text { ஸे }}{\text { ஸे }}$ & 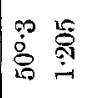 & $\vec{c}$ & 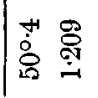 & $\stackrel{8}{8}$ \\
\hline & + & 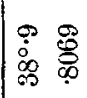 & $\stackrel{\text { ô }}{\dot{\sim}}$ & $\begin{array}{ll}5 & 9 \\
0 & 0 \\
\infty & 8 \\
\infty & 0\end{array}$ & $\underset{8}{8}$ & 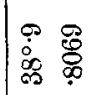 & $\underset{\phi}{S}$ \\
\hline & $\$$ & 灾 & $\stackrel{\text { ڤo }}{\sigma}$ & 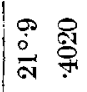 & $\vec{\circ}$ & 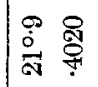 & $\vec{\circ}$ \\
\hline & $\begin{array}{c}\vdots \\
\vdots \\
\vdots \\
\vdots \\
0 \\
. \frac{1}{\infty}\end{array}$ & 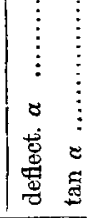 & 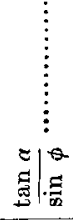 & 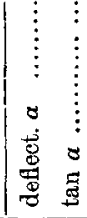 & 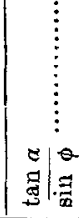 & 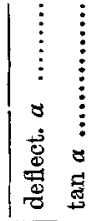 & 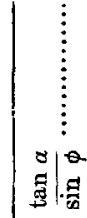 \\
\hline \multicolumn{2}{|c|}{ 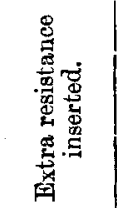 } & \multicolumn{2}{|c|}{0} & & $\begin{array}{l}\dot{g} \\
\dot{\Xi} \\
\text { की } \\
\dot{0}\end{array}$ & \multicolumn{2}{|c|}{ 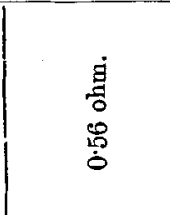 } \\
\hline \multicolumn{2}{|c|}{ 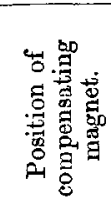 } & \multicolumn{2}{|c|}{ 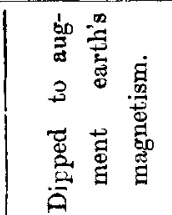 } & \multicolumn{2}{|c|}{ 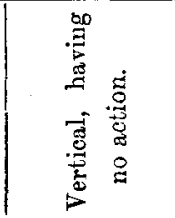 } & \multicolumn{2}{|c|}{ 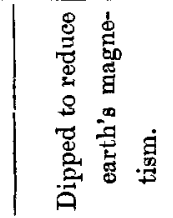 } \\
\hline
\end{tabular}


Table V. shows that the degree of accuracy did not materially differ under the three varying conditions. The magnet therefore does not appreciably interfere with the measurements. The mean error of all three positions of the magnet is 0.22 per cent., which is very low.

In conclusion, I may mention that a smaller model of the galvanometer, intended for practical use, is now being made, which will contain all the recent improvements, viz. the finewire coil besides the solid ring, the tangent-scale, the secantmarks, the air-damping, and the compensating-magnet. The latter will be so arranged that the "constant" will be considerably increased as compared with that due to the earth's magnetism alone; thus the needle should be much less influenced by outer disturbances than before.

Woolwich, June 1883.

XIV. The Influence of Current, Temperature, and Strength of Electrolyte on the Area of Electrification. By ALFRED TRIBe, F.Inst.C., Lecturer on Chemistry in Dulvich College.

I $\mathrm{N}$ the study of the subject of this paper I have employed 1 the "electro-chemical method" described by me in the Philosophical Magazine, 1881, xi. p. 446. It will be remembered that by this method images of the electrifications produced on metallic plates are rendered evident to the eye, and also that I have almost invariably employed as analyzers plates of silver, and as the electrolyte a solution of copper sulphate. The areas of the electrifications were found by measuring the copper and peroxide of silver respectively deposited or formed on the analyzing plate, the copper giving the area of the - electrification, and the silver peroxide that of the + electrification. The sum of the two electrifications subtracted from the total area of the plate, it will be seen, gives the area of non-electrification, $i$. e. the intermedial space, or that part of the plate which separates the + and - , and where the electromotive force is incapable of initiating electro-chemical action. These measurements are of course only relative.

The following conditions were common to the several experiments to be described:- an electrolytic cell 120 millim. broad, 128 deep and 305 long, filled to within 8 millim. with copper-sulphate solution; copper electrodes of the same area as the ends of the cell; a plate (analyzer) of fine silver, $67 \times 7$ millim., weighing 0.75 gram, placed lengthwise midway between the electrodes, and between the surface of the liquid and the bottom of the cell. The time of each experiment was six minutes. The diagram shows the general 